\title{
Cantrell syndrome in the first trimester of pregnancy: imagistic findings and literature review
}

\author{
Mihaela Grigore', Romeo Micu², Daniela Roxana Matasariu', Odetta Duma ${ }^{3}$, Anca Lucia \\ Chicea $^{4}$, Radu Chicea ${ }^{4}$
}

${ }^{1}$ Department of Obstetrics and Gynecology, "Grigore T. Popa" University of Medicine and Pharmacy Iasi, ${ }^{2}$ Department of Obstetrics and Gynecology, "Iuliu Hatieganu" University of Medicine and Pharmacy Cluj, ${ }^{3}$ Department of Epidemiology, "Grigore T. Popa" University of Medicine and Pharmacy Iasi, ${ }^{4}$ Department of Obstetrics and Gynecology, University of Medicine "Lucian Blaga", Sibiu, Romania

\begin{abstract}
Pentalogy of Cantrell (POC) is a rare condition characterized by complete or partial expression of 5 types of congenital birth defects originating in (1) the lower sternum, (2) the anterior diaphragm, (3) the diaphragmatic pericardium, (4) the midline/ventral supraumbilical abdominal wall region, and (5) the heart. POC can be diagnosed antenatally by means of ultrasonography (US), the task being difficult if defects are minor. Advances in the field of US and the introduction of the first morphology trimester as state-of-the-art pregnancy monitoring, facilitate the early diagnosis of this condition. We performed a systematic review on 67 reported cases of POC diagnosed in the first trimester of pregnancy (published from January 1980 to July 2019). The aim of our systematic review was twofold: to assess the main US findings in the first trimester of pregnancy and to increase awareness of early diagnostic possibilities. Our study showed that POC can be diagnosed in the first trimester of pregnancy based on key US findings such as the association between omphalocele and ectopia cordis. When these two anomalies are present, increased nuchal translucency can also be considered a marker of POC in the first trimester.

Keywords: Pentalogy of Cantrell; first trimester; ectopia cordis; abdominal wall defects; nuchal translucency
\end{abstract}

\section{Introduction}

Pentalogy of Cantrell (POC), also called Cantrell syndrome, is a rare, congenital anomaly, originally defined by James R. Cantrell in 1958 [1]. At that time, Cantrell encountered a number of cases in which 5 types of congenital birth defects were expressed completely or partially, originating in (1) the lower sternum, (2) the anterior diaphragm, (3) the diaphragmatic pericardium, (4) the

Received 20.11.2019 Accepted 09.01.2020

Med Ultrason

2020, Vol. 22, No 2, 189-196

Corresponding author: Romeo Micu, MD, PhD, Assoc. Prof.

University of Medicine and Pharmacy

"Iuliu Hatieganu" Cluj, Romania

Department of Obstetrics and Gynecology

Victor Babeș 8 Str, Cluj-Napoca 400000

Tel: +40744563121 midline/ventral supraumbilical abdominal wall region, and (5) the heart.

The precise etiology of this condition is not known; the syndrome is thought to be due to the faulty development of the mesoderm at an early stage of embryonic life [1]. Although the reported cases are sporadic, gene mutations on X chromosome are suspected to be involved [2]. The prevalence of POC is 1 in 5.5 million live births; approximately 250 cases have been documented since 1958 until 2009, of which $72 \%$ in the United States and Europe, and the rest of them in Asia [3,4].

POC can be diagnosed antenatally by means of ultrasonography (US), the task being difficult if defects are minor. Advances in the field of US and the introduction of the first morphology trimester as state-of-the-art pregnancy monitoring, facilitate the early diagnosis of this condition. Indeed, in recent years, several cases of POC 
diagnosed in the first trimester of pregnancy have been published.

The purpose of our systematic review was twofold: to increase awareness of early diagnostic possibilities and to assess the main US findings in the first trimester of pregnancy. Due to the ability of US to diagnose this syndrome before viability, the technique allows the parents to consider the option of terminating the pregnancy.

\section{Material and method}

\section{Search strategy}

In this systematic review, we followed the guidelines for Preferred Reporting Items for Systematic Reviews and Meta-Analyses [5]. The bibliographic databases PubMed, Embase and Google Scholar were searched using a combination of key words and text related to "Cantrell pentalogy", "Cantrell syndrome", "early pregnancy", "first trimester of pregnancy". The time period surveyed was from January 1980 to July 2019. We also included review articles already published on this subject and their reference lists were further retrieved and analysed. Moreover, we contacted the corresponding authors of several case reports requesting more information. We received one useful response, which was included in our database. Formal approval from the Ethics Committee at our institution was not required since this was a meta-analytical research effort. We used Pierson tools for evaluating the validity of a case report based on five components: documentation, uniqueness, objectivity, interpretation and educational value, resulting in a score with a maximum of 10 . A score above 5 was suggested indicate a valid case report.

In order to be included in our review, all the initially eligible studies had to fulfil the following criteria: 1) to feature cases of POC diagnosed in the first trimester of pregnancy (until 15 weeks of amenorrhea) and 2) the POC diagnosis to be confirmed by pathological examination of the fetus or newborn.

Studies were excluded from our review if the POC diagnosis had been established in the second or third trimester of pregnancy. Also excluded were studies in which a component of the condition had been observed early, but the actual prenatal diagnosis was established later than the first trimester.

The main objective of the study has been to appraise which are the relevant imagistic findings of POC in the first trimester of pregnancy. The secondary outcome has been to review the management of such cases.

Two of the review co-authors (MG and RDM) screened the abstracts and inspected the full texts of the selected articles to assess their relevance based on the inclusion criteria. We then resolved uncertainties and differences of opinion through discussion between coauthors MG, RDM and RM.

\section{Statistical analysis}

The data were collected and analysed using the SPSS program, version 21.0 and Microsoft Excel 2016 for Windows. Means, standard deviations and percentages were used for descriptive analysis. Comparative analysis was performed using the chi square test. For correlation analyses we used Pearson and Spearman correlations. The significance threshold was set to a $\mathrm{p}$ value of 0.05 or less.

\section{Results}

PubMed, Google Scolar and Embase searches yielded 10,303 results, of which 9,553 were excluded based on analysis of titles and abstracts. We took into consideration 750 articles, of which we then selected 88 articles for closer inspection. Of these, 53 articles were included in this study (fig 1). Overall, we systematically reviewed 67 cases: 66 from the literature and one from our institution [6-57]. The main anomalies that define POC diagnosed in the first trimester of pregnancy are described in Supplementary Table I, on the journal site.

The mean age of the patients at the time of diagnosis was $29.3 \pm 5.9$ (ranging between 20-43) and the mean age of the pregnancy at the time of diagnosis was $12.2 \pm 1.1$ weeks of gestation. There were 12 twin pregnancies, of which 6 monozygotic and 6 dizygotic. In one of the dizogotic pregnancies both fetuses had POC. Regarding the gender, the male/female ratio was 1.37/1.

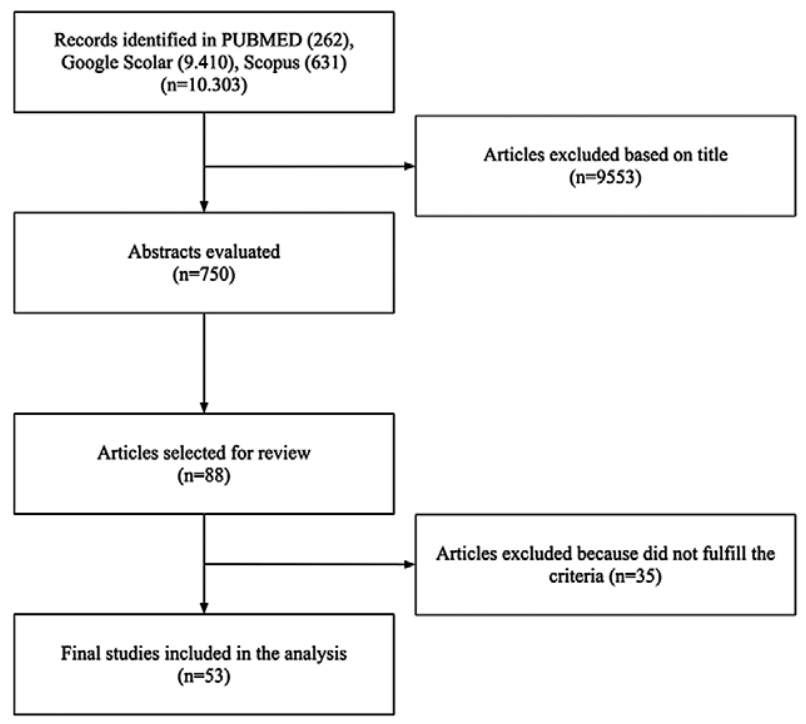

Fig 1. Study flow diagram. 
The karyotype analysis was performed in 38 of the 67 cases $(56.71 \%)$, and karyotype anomalies were discovered in 2 cases (trisomy 21). As the other 36 cases were normal, the ratio of karyotype anomalies was $1 / 18$. No significant correlation was found between the age of the pregnant women and the number of karyotype anomalies $(\mathrm{r}=0.03)$.

\section{US findings}

The main anomalies that define POC diagnosed in the first trimester of pregnancy are as follows:

\section{Ectopia cordis}

Ectopia cordis was detected by US in all the cases reported (fig 2) [6-57]. In six cases $(8.95 \%)$ the hearth protrusion was incomplete $[13,16,19,24,28]$.

\section{Abdominal wall defects}

In 64 cases abdominal wall defects were detected: omphalocele in 59 cases (92.18\%) (fig 3) [6-14,16-27, $29-36,38-41,43-55,57]$, gastrosquisis in 4 cases $(6.25 \%)$ $[15,34,37,42]$ and one case of laparoschizis $(1.56 \%)$ [25].

\section{Sternal malformations}

Sternal malformations were described in one third of the cases (23 patients, 34.32\%). The defective formation of the lower half of the sternum (cleft defect) was present in 20 fetuses [6,11,16,18,19,26,28,31,34,35,40,48,50, 57], while complete sternal aplasia was found in 3 cases $[8,9,38]$.

\section{Diaphragmatic and pericardial defects}

Diaphragmatic and pericardial defects were noted in utero in 11 fetuses (16.41\%) [14,16,35,38,48-50] and in 10 cases $(14.92 \%)$, respectively $[14,16,32,35,48,50]$.

Intracardiac anomalies

In 9 cases $(13.43 \%)$ intracardiac anomalies were detected: 5 cases of ventricular septal defects (VSD) $(55.55 \%)[16,22,32,44,46]$, of which 2 had also atrial septal defect (DSA) (22.22\%) [16,32], 1 case of dextrocardia (11.11\%) [28], 1 case of Fallot Tetralogy (11.11\%) [46], 1 case of single-cavity heart without a septum (11.11\%) [47] and 1 case of common atrioventricular valve with single right ventricle, double outlet right ventricle (11.11\%) [28].

\section{Nuchal translucency}

Nuchal translucency was measured and reported in 44 cases: the results were abnormal $(>2.5 \mathrm{~mm}$, including cystic hygroma) in 39 cases $(88.63 \%)[1,10-13,16,17,22$, 25,26,28-30,34-36,41,43-47,50,53,54,56,57].

\section{Umbilical cord defects}

The umbilical cord anomalies found in the first trimester of pregnancy are presented in Table I.

Other associated anomalies

Other associated anomalies diagnosed by US in the first trimester of pregnancy are presented in Table II.

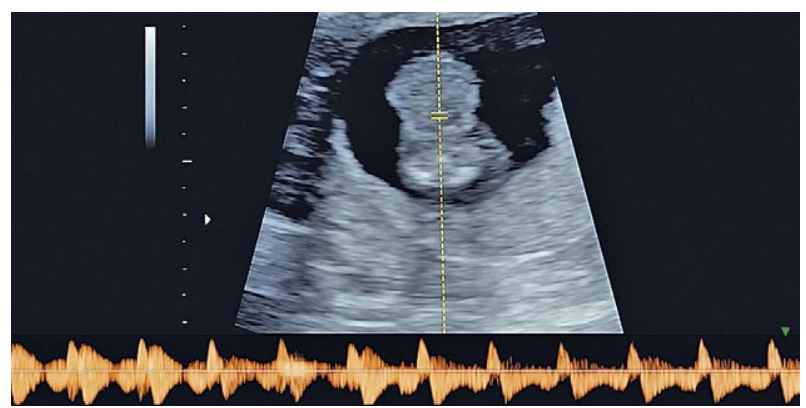

Fig 2. Pregnancy 12 weeks of amenorrhea - ectopia cordis (the heart is located inside the abdominal wall defect)

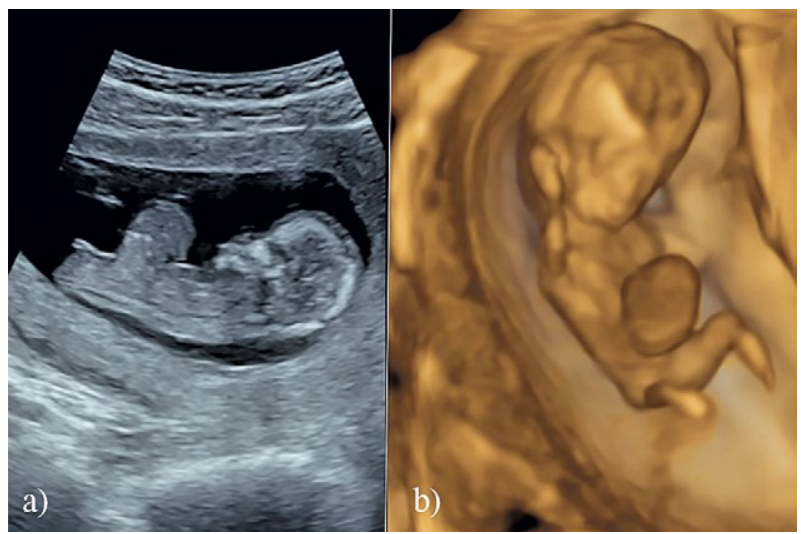

Fig 3. Pregnancy 12 weeks of amenorrhea omphalocele: a) grey scale ultrasound; b) three-dimensional ultrasound examination enables a better image of the omphalocele

Table I. Umbilical cord anomalies

\begin{tabular}{ll}
\hline $\begin{array}{l}\text { Umbilical } \\
\text { cord anomaly }\end{array}$ & $\begin{array}{l}\text { Number of cases } \\
\text { [reference] }\end{array}$ \\
\hline Single umbilical artery & $4[25,34,54]$ \\
Short & $6[25,34,47,54]$ \\
Hypercoilled & $1[28]$ \\
Abnormally placed & $1[47]$ \\
(directly join the right atrium) & \\
\hline
\end{tabular}

Management of POC diagnosed in the first trimester of pregnancy

In 50 cases, after counselling, the parents decided to terminate the pregnancies, while 10 couples decided to continue with the pregnancies despite being informed about the poor prognosis of this condition. Of these, 3 resulted in stillbirths and the other 7 were delivered either prematurely or at term.

\section{Discussion}

The prevalence of POC in the first trimester of pregnancy is higher than at the end of pregnancy or after birth because large defects are associated with stillbirths and 
high mortality rates. Sepulveda et al identified 4 cases of POC among 15,000 fetuses screened in the first trimester of pregnancy. However, this increased prevalence $(\sim 1$ in 7,500 cases) is not representative for the general population because the reporting centre, being a reference centre, concentrates all cases with fetal malformation from that region [35]. Recently, Syngelaki et al reviewed the structural anomalies in a general population of 100,997 singleton pregnancies following a standardized protocol at 11-13 weeks of gestation and detected 2 cases of POC ( $\sim 1$ in 50,500 cases) [56]. In our review, stillbirths occurred in approximately a third (30\%) of those cases in which POC had been identified in the first trimester but the parents decided to continue the pregnancy.

The male-to-female ratio has been estimated at 1.35:1 by Vasquez-Jimenez et al, who analysed 80 patients with POC, and at 2:1 by Toyama et al $[58,59]$. Based on the cases we have included in review, all diagnosed in the first trimester of pregnancy, we calculated a male/female ratio of 1.37:1.

In 12 of the 67 analysed cases, the diagnosis was established on twin pregnancies and in four of the twin pregnancies, were obtained with in vitro fertilisation. A systematic review showed that birth defects are more common when assisted reproductive techniques are used. One possible explanation points to the bypassing of the natural selection of the gametes: the early embryonic development takes place in laboratory conditions and continues in the uterus in a hyperstimulated hormonal environment [60].

When the constellation of POC malformations is diagnosed in the first trimester, fetal chromosomal analysis should be considered (either by invasive or non-invasive techniques) based on reported associations with trisomy 21 and $18[61,62]$. We found that the karyotype analysis was performed in $56.71 \%$ of cases and 2 anomalies were discovered.

In POC, the abdominal wall defects are represented by omphalocele, diastasis recti, epigastric hernia, umbilical hernia or combined defects [39]. These defects can be easily diagnosed by US during the first trimester of pregnancy [63]. Until 12 weeks of amenorrhea the elongation of the midgut with herniation into the base of the umbilical cord is still in progress in the normal fetus [64]. In all reported cases of POC diagnosed in the first trimester of pregnancy, the abdominal wall defects were diagnosed by US and the most frequent was the omphalocele $(92.18 \%)$. We can, therefore, consider the omphalocele an important US marker for the diagnosis of POC in the first trimester of pregnancy. However, it is important to distinguish POC from other possible abdominal wall defects like gastroschizis, omphalocele or body-stalk anomalies [65].
Table II. Associated abnormalities with pentalogy of Cantrell

\begin{tabular}{ll}
\hline Associated abnormalities & Number of cases [reference] \\
\hline CNS anomaly & \\
anencephaly & $3[23,31,33]$ \\
myelomeningocele & $2[43,54]$ \\
exencephaly & $5[7,14,15,18,40]$ \\
other & $3[12,19,52]$ \\
Scheletal anomaly & \\
spina bifida & $2[23,34]$ \\
cranioschisis & $3[5,18,52]$ \\
spinal disraphy & $1[15]$ \\
club foot & $6[14,19,20,26,27,54]$ \\
scoliosis & $10[12,15,20,27,34,36,44,45,54]$ \\
defect middle plane & $1[37]$ \\
spinal curvature/spine & $2[40,43]$ \\
deformed and short & \\
acrania & $1[31]$ \\
equinovarus deformity & $3[26,31,44]$ \\
abducted lower limbs & $1[34]$ \\
hypoplastic/absent femur/ & $1[27]$ \\
tibia/fibula & \\
Facial malformation & \\
nasal bone absent & $2[37,57]$ \\
cleft lip and palate & $2[19,48]$ \\
unilateral anophthalmia & $1[52]$ \\
\hline & \\
\hline
\end{tabular}

Sternal malformations, identified in $34.32 \%$ of reported cases, include bifid sternum, absent xiphoid process, short sternum and defective formation of the lower third [66]. A sternal defect can lead to ectopia cordis, which means that the heart is completely or partially outside the thoracic cavity. Benett et al [67], in 1991, made the first description of fetal ectopia cordis in the first trimester of pregnancy (at 12 weeks of gestation) by means of transbodminal US. Later, in 1997, Liang et al proved that it is possible to diagnose ectopia cordis even earlier, at 10 weeks of gestation [68]. In all the reported cases diagnosed in the first trimester, ectopia cordis was detected via US. We consider that the simultaneous presence of ectopia cordis and omphalocele is highly indicative for POC. Thus, ectopia cordis (partial or complete) should be considered as a marker for the diagnosis of POC in early pregnancy.

Diaphragmatic defects and pericardial defects are difficult to diagnose in the first trimester of pregnancy by means of US. According to our review such defects were detected in $16.41 \%$ and $14.92 \%$ of cases, respectively.

Intracardiac anomalies are a main feature of POC. In the first trimester of pregnancy, we found that such anomalies have been described in $13.43 \%$ of cases. Intracardiac anomalies are, however, difficult to diagnose in 
the first trimester of pregnancy, even at the pathological examination, because of the small size of the heart.

Increased nuchal translucency (NT) in the first trimester of pregnancy is associated with chromosomal anomalies and is also predictive for other non-chromosomal anomalies such as cardiac defects [11]. Increased NT is not an unexpected finding in POC and can be considered an indirect sign of cardiac malformation. It may be the result of venous congestion due to cardiac failure and associated cardiac defects [13]. In some cases of POC diagnosed in the first trimester, it was the increased NT that generated early attention to the fetus [16]. From a total of 67 case reports, 44 provided NT measurements $(65.67 \%)$, and NT was increased in $88.63 \%$ of these cases. Mention must be made that, from the 24 cases lacking NT-related information, in 9 cases the fetus had a cranial malformation (exencephaly, acrania), which may explain the impossibility of measuring this parameter. Also, we found no statistical significance between the age of the patient and increased NT ( $>>0.05)$. Our suggestion is to include this US marker among those used for the diagnosis of POS in the first trimester pregnancy.

The crown rump length (CRL) can be smaller than expected in POC during the first trimester of pregnancy, possibly because of the associated anomalies of the spine (scoliosis). If scoliosis is present, the crown rump length should be measured in two segments, which are then added up. Sarkar et al consider that the shortened biometry is the result of true intrinsic growth restriction [12].

Anomalies of the umbilical cord (UC) have also been reported in POC, especially in cases with ectopia cordis. This association can be explained by the fact that the embryonic period in which POC develops (Carnegie stage 6) coincides with the beginning of the normal development of the UC itself and the spiral course of its vessels [25]. In the first trimester of pregnancy, umbilical cord anomalies were detected in 12 cases (17.91\%).

Furthermore, searching for associated anomalies is mandatory in Cantrell syndrome since prognosis depends on the severity of the lesions. [50]. According to our review, the main associated anomalies diagnosed in the first trimester of pregnancy were cranial (12 cases, $17.9 \%$ ), facial ( 5 cases, $7.46 \%$ ) and skeletal (31 cases, $46.26 \%$ ).

Although two-dimensional (2D) US is the method of choice for detecting abdominal wall defects, threedimensional (3D) US provide a better visualization of complex associated malformations. In POC, 3D US in surface mode clearly show defects such as ectopia cordis and omphalocele, and they are also useful for identifying associated anomalies such as cranioschisis or excencefaly [18]. In turn, 3D US in transparent mode is more suitable than 2D for detecting bone malformations [69].
The prognosis in POC is reserved and depends on how many of the anomalies of the pentalogy and their associated anomalies are concurrently present. Only few cases of survivors are reported [59,70,71], and they were mainly incomplete forms of POC. Also, all the survivors had to undergo prolonged hospitalization with multiple surgical interventions. Subsequently, there were still significant degrees of long-term disability [16].

In light of such knowledge and experience, it is generally accepted that, when the diagnosis is established in the first trimester, the termination of the pregnancy is an appropriate decision. Parents should, therefore, receive adequate information and counselling about the poor prognosis of this condition [72].

When POC occurs in a twin pregnancy, the decision and management are more difficult, especially with monochorionic twins. The presence of POC in one twin can increase the risk for the healthy twin by causing damage or a premature birth (e.g. fetal exsanguination of the healthy twin after the sudden death of the malformed twin) [46]. In such cases, it is important to carefully assess the other twin before making a decision. In dichorionic twin pregnancies, the technique for selective feticide can be the fetal cord injection of potassium chloride. However, in monochorionic twins, this technique cannot be used because the healthy twin can be affected through placental vascular anastomoses [73]. In these cases, selective feticide is performed by methods that produce cord occlusion, and thus avoid the eventual exsanguination of the surviving fetus into the dead fetus [74]. The method of choice is bipolar coagulation, ideally after the 18th week of gestation for better odds of survival of the healthy twin [75].

\section{Conclusion}

POC can be diagnosed in the first trimester of pregnancy based on key US findings such as the association between omphalocele and ectopia cordis. When these two anomalies are present, increased NT can also be considered a useful sonographic marker of POC. The possibility of diagnosing this syndrome before viability allows the parents to consider the option of terminating the pregnancy.

\section{Conflict of authors: none}

\section{References}

1. Cantrell JR, Haller JA, Ravitch MM. A syndrome of congenital defects involving the abdominal wall, sternum, diaphragm, pericardium and heart. Surg Gynecol Obstet 1958;107:602-614. 
2. Carmi R, Barbash A, Mares AJ. The thoracoabdominal syndrome (TAS): a new X-linked dominant disorder. Am J Med Genet 1990;36:109-114.

3. Carmi R, Boughman JA. Pentalogy of Cantrell and associated midline anomalies: a possible ventral midline developmental field. Am J Med Genet 1992;42:90-95.

4. Mitsukawa N, Yasunaga H, Tananari Y. Chest wall reconstruction in a patient with Cantrell syndrome. J Plast Reconstr Aesthet Surg 2009;62:814-818.

5. Moher D, Liberati A, Tetzlaff J, Altman DG; PRISMA Group. Preferred reporting items for systematic reviews and meta-analyses: the PRISMA statement. PLoS Med 2009;6:e1000097.

6. Hsieh YY, Lee CC, Chang CC, Tsai HD, Hsu TY, Tsai CH. Prenatal sonographic diagnosis of Cantrell's pentalogy with cystic hygroma in the first trimester. J Clin Ultrasound 1998;26:409-412.

7. Bognoni V, Quartuccio A, Quartuccio A. First-trimester sonographic diagnosis of Cantrell's pentalogy with exencephaly. J Clin Ultrasound 1999;27:276-278.

8. Yamasaki A, Pedreira AL, Muller R, Machado MV, Schultz R, Cha SC. P115 First trimester diagnosis of the Pentalogy of Cantrell. 10th World Congress on Ultrasound in Obstetrics and Gynecology. 4-7 October 2000, Zagreb, Croatia. Posters. Ultrasound Obstet Gynecol 2000:91. doi: 10.1046/j.1469-0705.2000.00004-1-114.x

9. Onderoglu L, Baykal C, Tulunay G, Talim B, Kale G. Prenatal diagnosis of Cantrell's pentalogy: a case report. Turk J Pediatr 2003;45:357-358.

10. Markov D, Chernev T, Dimitrova V, Mazneǐkova V. Pentalogy of Cantrell associated with increased nuchal translucency at 12+1 w.g. Akus Ginekol (Sofiia) 2004;43:34-36.

11. Staboulidou I, Wüstemann M, Schmidt $P$, Günter $H H$, Scharf A. Increased fetal nuchal translucency as a predictor of Cantrell's pentology - case report. Z Geburtshilfe Neonatol 2005;209:231-234.

12. Sarkar P, Bastin J, Katoch D, Pal A. Pentalogy of Cantrell: diagnosis in the first trimester. J Obstet Gynaecol 2005;25:812-813.

13. Desselle C, Herve P, Toutain A, Lardy H, Sembely C, Perrotin F. Pentalogy of Cantrell: Sonographic Assessment. J Clin Ultrasound 2007;35:216-220.

14. Rashid RM, Muraskas JK. Multiple vascular accidents: Pentalogy of Cantrell in one twin with left sided colonic atresia in the second twin. J Perinat Med 2007;35:162-163.

15. Doganay S, Kantarci M, Tanriverdi EC. Pentalogy of cantrell with craniorachischisis: MRI and ultrasonography findings. Ultraschall Med 2008;29 Suppl 5:278-280.

16. Zidere V, Allan LD. Changing findings in pentalogy of Cantrell in fetal life. Ultrasound Obstet Gynecol 2008;32:835-837.

17. Peixoto-Filho FM, do Cima LC, Nakamura-Pereira M. Prenatal diagnosis of Pentalogy of Cantrell in the first trimester: is 3-dimensional sonography needed? J Clin Ultrasound 2009;37:112-114.

18. Murata S, Nakata M, Sumie M, Mastsuabra M, Sugino N. Prenatal diagnosis of Pentalogy of Cantrell with craniora- chischisis by three-dimensional ultrasonography in the first trimester. Taiwan J Obstet Gynecol 2009;48:317-318.

19. Stein W, Haller F, Hawighorst T, Emons G. Pentalogy of Cantrell vs. limb body wall complex: differential diagnosis of a severe malformation in early pregnancy. Ultraschall Med 2009;30:598-601.

20. Gün I, Kurdoğlu M, Müngen E, Muhcu M, Babacan A, Atay V. Prenatal diagnosis of vertebral deformities associated with pentalogy of Cantrell: the role of three-dimensional sonography? J Clin Ultrasound 2010;38:446-449.

21. Rossi A, Forzano L, Fachechi G, Veronese P, Arteni A, Marchesoni D. P34.03 Incomplete pentalogy of Cantrell during first trimester of pregnancy: case report. Ultrasound Obstet Gynecol 2010;36 (Suppl 1):168-305.

22. Arıkan DC, Yancar S, Güçer F, Zencir E, Beyazıt H. Prenatal diagnosis of pentalogy of Cantrell with increased nuchal translucency: case report. Gynecol Obstet Reprod Med 2011;17:173-176.

23. Atis A, Demirayak G, Saglam B, Aksoy F, Sen C. Craniorachischisis with a variant of pentalogy of Cantrell, with lung extrophy. Fetal Pediatr Pathol 2011;30:431-436.

24. De Keersmaecker B, Segaert A, Dewulf V, Denys B, Thys J. P07.01: Incomplete pentalogy of Cantrell during the first trimester of pregnancy: a case report. Ultrasound Obstet Gynecol 2011;38:190.

25. Brochut AC, Baumann MU, Kuhn A, et al. Pentalogy or Hexalogy of Cantrell? Pediatr Dev Pathol 2011;14:396401.

26. Şimşek ÖY, Karaer A, Turhan U, Celik O. First trimester diagnosis of pentalogy of cantrell: a case report. Perinatal Journal 2011;19:81-84.

27. Ergenoğlu MA, Yeniel AÖ, Peker N, Kazandı M, Akercan F, Sağol S. Prenatal diagnosis of Cantrell pentalogy in first trimester screening: case report and review of literature. J Turk Ger Gynecol Assoc 2012;13:145-148.

28. Gjørup V, Ramsing M, Vestergaard E, Vogel I, Petersen OB. P26.16: First trimester diagnosis of Pentalogy of Cantrell and hypercoiling of the umbilical cord. Ultrasound Obstet Gynecol 2012;40:272-273.

29. Di Spiezio Sardo A, Paladini D, Zizolfi B, Spinelli M, Nappi C. Pentalogy of Cantrell: embryofetoscopic diagnosis. J Minim Invasive Gynecol 2013;20:248-251.

30. Uysal A, Uysal F, Gencer M. Cantrell's syndrome revisited: a case with increased nuchal fold diagnosed in the first trimester. Perinatal Journal 2013;21:32-34.

31. Cakmak B, Ozsoy Z, Nacar MC, Demirturk F. First trimester diagnosis of pentalogy of Cantrell: a rare case associated with neural tube defect. Perinatal Journal 2013;21:38-41.

32. Chandran S, Ari D. Pentalogy of Cantrell: an extremely rare congenital anomaly. J Clin Neonatol. 2013;2:95-97.

33. Chen CP, Huang MC, Chern SR, Wu PS, Su JW, Wang W. Discordant anencephaly and Cantrell syndrome in monozygotic twins conceived by ICSI and IVF-ET. Taiwan J Obstet Gynecol 2013;52:297-299.

34. Kubba T, Khalil A, Abu-Rustum R, et al. Prenatal diagnosis of pentalogy of Cantrell at 11-13 weeks: Evidence for a hexalogy. J Obstet Gynaecol 2013;33:85-86. 
35. Sepulveda W, Wong AE, Simonetti L, Gomez, E, Dezerega V, Gutierrez J. Ectopia cordis in a first-trimester sonographic screening program for aneuploidy. J Ultrasound Med 2013;32:865-871.

36. Yang TY, Tsai PY, Cheng YC, Chang FM, Chang CH. Prenatal diagnosis of pentalogy of Cantrell using three-dimensional ultrasound. Taiwan J Obstet Gynecol 2013;52:131132.

37. Reyes Bacardi K, Martinez Vidal I, Garcia Guevara C, Martinez Nieves Y. Prenatal diagnosis of pentalogy of Cantrell. Rev Cubana Pediatr 2014;86:86-92.

38. Bakacak M, Bostanci MS, Serin S, Goya C, Bakacak Z, Avci F. Ectopia cordis and pentalogy of Cantrell: report of two cases. Int J Women's Health Reprod Sci2014;2:323-325.

39. Cakiroglu Y, Doger E, Yildirim Kopuk S, Babaoglu K, Caliskan E, Yucesoy G. Prenatal diagnosis of Cantrell's pentalogy associated with agenesis of left limb in a twin pregnancy. Case Rep Obstet Gynecol 2014;2014:314284.

40. Cekmez Y, Tos T, Yilmaz Z, Pişkinpaşa N, Küçüközkan T. Pentalogy of Cantrell diagnosed in the first trimester of pregnancy. Int J Case Rep Imag 2014;5:215-217.

41. Ensari TA, Uygur D, Erdinç ASÖ, Kırbas A, Erkaya S, Danisman N. Pentalogy of Cantrell in one fetus of a twin pregnancy diagnosed at first trimester. J Obstet Gynecol Neonatal Nurs2014;11:105-107.

42. Martins CF, Serras I, Santos AV, Costa Braga A. Pentalogy of Cantrell: the complete spectrum. BMJ Case Rep 2014;2014:bcr2014207556.

43. Biberoglu E, Kirbas A, Daglar K, Uygur D, Yucel A. Prenatal diagnosis of complete Cantrell's pentalogy in an IVF/ ICSI co-twin. J Cases Obstet Gynecol 2015;2:78-80.

44. Pekin AT, Kerimoglu OS, Yilmaz SA, Kebapcilar AG, Bakbak BG, Celik C. Pentalogy of Cantrell accompanied by scoliosis and pes equinovarus deformity at 12 weeks gestation. Clin Exp Obstet Gynecol 2015;42:392-394.

45. Türkçapar AF, Sargın Oruc A, Öksüzoglu A, Danışman N. Diagnosis of pentalogy of Cantrell in the first trimester using transvaginal sonography and color Doppler. Case Rep Obstet Gynecol 2015;2015:179298.

46. Abehsera D, de la Calle M, Rodríguez R, Revello R, Brunel I, Bartha JL. Bipolar cord coagulation for selective feticide in a monochorionic twin pregnancy complicated by pentalogy of Cantrell. Taiwan J Obstet Gynecol 2016;55:135-137.

47. Batur A, Goya C, Yavuz A, Hamidi C, Cetincakmak MG. Concurrence of prenatally diagnosed Cantrell pentalogy and short and tight umbilical cord: a possible case of hexalogy. Eastern J Med 2016;21:138-140.

48. Delibas IB, Isaoglu U, Tanriverdi EC, Yilmaz M. A case of Cantrell syndrome diagnosed in the first trimester. Clin Exp Obstet Gynecol 2016;43:612-613.

49. Lertvutivivat S, Chanthasenanont A, Pongrojpaw D, Suwannarurk K. First trimester diagnosis of pentalogy of Cantrell (POC) by transabdominal 2-dimentional (2D) ultrasonography, first case report in Thailand. J Med Assoc Thai 2017;100 (Supp15): S273-S276.

50. Naren Satya SM, Mayilvaganan KR, Prathyusha IS, Gautam MS, Raidu D, Amough VN. A recurrent case of Pental- ogy of Cantrell: a rare case with sonological findings and review of literature. Pol J Radiol 2017;82:28-31.

51. Rezai S, Hughes AC, Hoge G, et al. Ultrasonographic diagnosis of fetuses with pentalogy of Cantrell and turner syndrome, dual case reports and review of literature. Obstet Gynecol Int J 2017;8:00290.

52. Grigore M, Furnica C, Esanu I, Gafitanu D. Pentalogy of Cantrell associated with unilateral anophthalmia. Case report and literature review. Medicine 2018;97:e11511.

53. Sinha P, Sibtain S. Cardia Ectopia with Omphalocele Detected at $11+5$ Weeks. J Soc Obstet Gynaecol Pak 2018;8:135-136.

54. Türkyilmaz G, Avcı S, Sivrıkoz T, et al. Prenatal diagnosis and management of ectopia cordis: varied presentation spectrum. Fetal Pediatr Pathol 2019;38:127-137.

55. Roux N, Grangé G, Salomon LJ, Rousseau V, Khen-Dunlop N, Beaudoin S. Early diagnosis of omphalocele: Prognostic value of the herniated viscera for associated anomalies. Gynecol Obstet Fertil Senol 2019;47:637-642.

56. Syngelaki A, Hammami A, Bower S, Zidere V, Akolekar R, Nicolaides KH. Diagnosis of fetal non-chromosomal abnormalities on routine ultrasound examination at 11-13 weeks' gestation. Ultrasound Obstet Gynecol 2019;54:468476.

57. Sreekala L. Diagnosis of pentalogy of Cantrell in first trimester ultrasound. BMH Med J 2019;6:91-93.

58. Toyama WM. Combined congenital defects of the anterior abdominal wall, sternum, diaphragm, pericardium, and heart: a case report and review of the syndrome. Pediatrics 1972;50:778-792.

59. Vazquez-Jimenez JF, Muehler EG, Daebritz S, et al. Cantrell's syndrome: a challenge to the surgeon. Ann Thorac Surg 1998;65:1178-1185.

60. Hansen M, Kurinczuk JJ, Milne E, de Klerk N, Bower C. Assisted reproductive technologies and the risk of birth defects- a systematic review and meta-analysis. Hum Reprod Update 2013;19:330-353.

61. Onderoğlu L, Baykal C, Tulunay G, Talim B, Kale G. Prenatal diagnosis of Cantrell's pentalogy: a case report. Turk J Pediatr 2003;45:357-358.

62. Fox JE, Gloster ES, Mirchandani R. Trisomy 18 with Cantrell pentalogy in a stillborn infant. Am J Med Genet 1988;31:391-394.

63. Grigore M, Iliev G, Gafiteanu D, Cojocaru C. The fetal abdominal wall defects using 2D and 3D ultrasound. Pictorial essay. Med Ultrason 2012;14:341-347.

64. Hertzberg BS, Nyberg DA, Neilsen IR. Ventral wall defects. In: Nyberg DA, McGahan JP, Pretorius DH, Pilu G (eds). Diagnostic imaging of fetal anomalies. Lippincott Williams \& Wilkins: Philadelphia, PA, 2003;507-546.

65. Emanuel PG, Garcia GI, Angtuaco TL. Prenatal detection of anterior abdominal wall defects with US. Radiographics 1995;15:517-530.

66. Singh N, Bera ML, Sachdev MS, Aggarwal N, Joshi R, and Kohli V. Pentalogy of cantrell with left ventricular diverticulum: a case report and review of literature. Congenit Heart Dis 2010;5:454-457. 
67. Bennett TL, Burlbaw J, Drake CK, Finley BE. Diagnosis of ectopia cordis at 12 weeks gestation using transabdominal ultrasonography with color flow Doppler. J Ultrasound Med 1991;10:695-696.

68. Liang RI, Huang SE, Chang FM. Prenatal diagnosis of ectopia cordis at 10 weeks of gestation using two-dimensional and three-dimensional ultrasonography. Ultrasound Obstet Gynecol 1997;10:137-139.

69. Xu HX, Zhang QP, Lu MD, Xiao XT. Comparison of two-dimensional and three-dimensional sonography in evaluating fetal malformations. J Clin Ultrasound 2002;30:515-525.

70. Grethel EJ, Hornberger LK, Farmer DL. Prenatal and postnatal management of a patient with Pentalogy of Cantrell and left ventricular aneurysm. A case report and literature review. Fetal Diagn Ther 2007;22:269-273.

71. Takaya J, Kitamura N, Tsuji K, et al. Pentalogy of Cantrell with a double-outlet right ventricle: 3.5 -year follow-up in a prenatally diagnosed patient. Eur J Pediatr 2008;167:103105.

72. Grigore M, Gafitanu D, Socolov D, Grigore A, Nemeti G, Micu R. The role of 4D US in evaluation of fetal movements and facial expressions and their relationship with fetal neurobehaviour. Med Ultrason 2018;20:88-94.

73. Sepulveda W, Corral E, Aiello H, et al. Intrafetal alcohol chemosclerosis of acardiac twins: a multicenter experience. Fetal Diagn Ther 2004; 19:448-452.

74. Rossi AC, D'Addario V. Umbilical cord occlusion for selective feticide in complicated monochorionic twins: a systematic review of literature. Am J Obstet Gynecol 2009;200:123-129.

75. Gallot D, Laurichesse H, Lemery D. Selective feticide in monochorionic twin pregnancies by ultrasound-guided umbilical cord occlusion. Ultrasound Obstet Gynecol 2003;22:484-488. 